\title{
Functional Classification of Neurons in the Mouse Lateral Cerebellar Nuclei
}

\author{
Marylka Uusisaari • Thomas Knöpfel
}

Published online: 30 November 2010

(C) The Author(s) 2010. This article is published with open access at Springerlink.com

\begin{abstract}
The deep cerebellar nuclei (DCN) are at the center of the cerebellum not only anatomically but also functionally. Classical anatomical studies have described different types of DCN neurons according to their expression of various marker proteins, but only recently have we begun to characterize these different cell types according to their electrophysiological properties. These efforts have benefited greatly from the availability of transgenic mouse lines that express green fluorescent protein under the control of the glutamic acid decarboxylase (GAD67) and glycine transporter (GlyT2) promoters, which are markers for GABAergic and glycinergic neurons, respectively. These studies have identified several types of neurons within the lateral cerebellar nuclei, each of which exhibits distinct active membrane properties. In addition to their differential use of neurotransmitters (glutamate, GABA, or glycine), these cell types also receive and provide synaptic information from different sources and to different targets.
\end{abstract}

Keywords Cerebellum · Cerebellar nuclei · GAD67 .

GlyT2 · GFP · Transgenic mouse · Electrophysiology .

Morphology

\section{Introduction}

Our understanding of cerebellar function has historically been based on the premise that the cerebellar cortex is the

M. Uusisaari · T. Knöpfel $(\triangle)$

Laboratory for Neuronal Circuit Dynamics,

RIKEN Brain Science Institute,

Wako-shi, Saitama 351-0198, Japan

e-mail: tknopfel@brain.riken.jp

\section{Uusisaari}

Theoretical and Experimental Neurobiology Unit,

OIST,

Onna, Okinawa 904-0412, Japan site of information processing, or at least memory storage and retrieval [1]. This corticocentric viewpoint assumes that cerebellar output is mainly carried by the projection neurons of the deep cerebellar nuclei (DCN). However, evidence clearly suggests that the DCN are not merely a relay station, but rather constitute a site of signal integration if not signal generation. Indeed, a role in adaptive information processing and perhaps pattern generation may be deduced from the presence of specific forms of synaptic plasticity within the DCN [2-4]. Understanding the information-processing capabilities of a neuronal circuit generally requires the elucidation of the distinct cell types that comprise it. Several excellent studies have made an effort to examine the diversity of DCN neurons using morphological staining $[5,6]$, either alone or in combination with electrophysiological recordings [7]. These studies have revealed considerable diversity of DCN neurons but have found only modest correlations between electrophysiological features and neuronal morphology, indicating that these neurons cannot be classified solely based on morphometric criteria [8]. To overcome this challenge, our laboratory took advantage of transgenic mouse lines that express fluorescent proteins under the promoters for glutamic acid decarboxylase (GAD67 [9]) and a glycine transporter (GlyT2 [10]), which are often used as markers for GABAergic and glycinergic neurons, respectively [11, 12]. A careful examination of cerebellar structures in GAD67-EGFP mice confirmed that all GABAergic (GABA-containing) neurons in the DCN express EGFP. Since we did not directly identify the transmitters released by these EGFPexpressing cells, and in keeping with the terminology applied in the original publications, we have addressed the various neuronal subtypes based on the presence of these markers (e.g., GAD67-positive, GAD+) rather than the most probable neurotransmitter (e.g., GABA). Neurons that were not identified by either of the two markers are 
likely to be glutamatergic (for a more detailed discussion see [12]).

The mouse DCN comprises three distinct nuclei (medial, interposed, and lateral), each of which features a specific composition of neurons of various sizes [13]. There are significant differences in gross anatomy and neuronal morphology between the three $\mathrm{DCN}$ - especially the lateral DCN, also known as the "dentate nucleus" in primates $[5,14]$. However, all of the DCN engage in two pathways of information flow (Fig. 1): the olivo-corticonucleo-olivary (OCNO) loop, and the pathway formed by mossy fibers, granule cell axons, Purkinje cells, and DCN projections to premotor nuclei $[1,15,16]$. These pathways are organized in compartments that follow the zonal topography of the cerebellar cortex, each of which is likely to be related to different modes of cerebellar function [17].

This review will compile work from our three original studies of the neuronal types found in the lateral cerebellar nucleus of the mouse as well as complementary information from other previous and concurrent studies, without attempting to comprehensively review the available literature on other features of the cerebellar nuclei. We will therefore focus primarily on four types of neurons identified in the mouse lateral DCN based on GAD67 and GlyT2 promoter activity, with the data from each neuron type indicated by color code: black, large GAD67-negative (putative non-GABAergic) DCN cells (GADnL); orange, small GAD67-negative DCN cells (GADnS); green, GAD67-positive (GAD+, GABAergic)

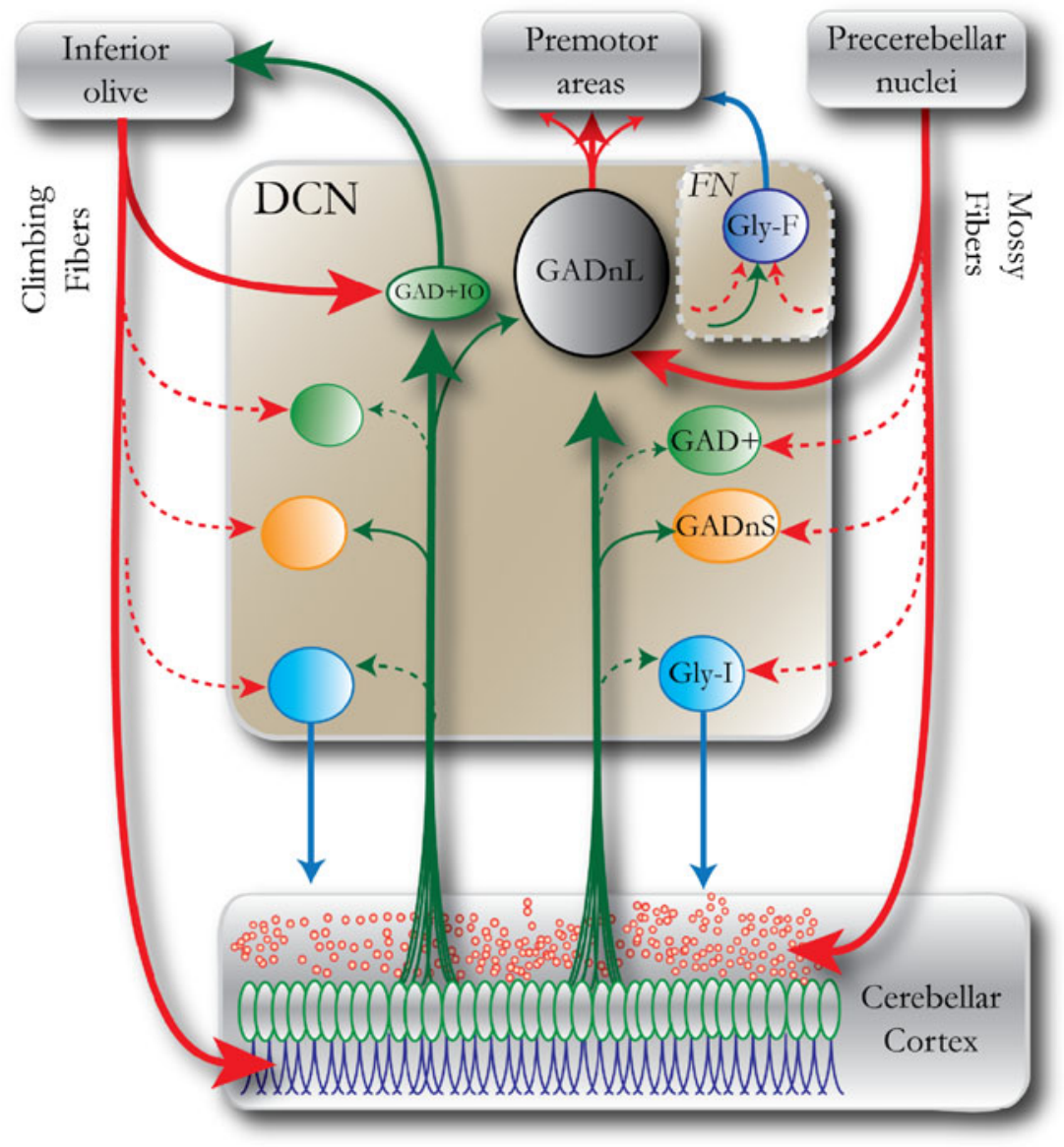

Fig. 1 Schematic drawing of the main neuron groups in the DCN including afferent and efferent connections, emphasizing the two topographically distinct routes of information flow: the OCNO loop (left) and the mossy fiber-cortico-nucleo-DCN pathway that mediates cerebellar output to premotor nuclei. Color coding and naming of DCN neurons follow a scheme presented in [11] and [48], which will be followed throughout this review. Red arrows denote glutamatergic (excitatory) axons; green arrows denote GABAergic (inhibitory) axons; and blue arrows denote glycinergic or mixed glycinergic/
GABAergic axons. Arrows with dashed lines denote connections that are of uncertain strength or have not been unequivocally demonstrated. Note that local axons of DCN neurons are not shown for the sake of illustrative clarity. GADnL large GAD67-negative cells, GADnS small GAD67-negative cells, GAD+ GAD67-positive (GABAergic) cells, Gly-I non-spontaneous GlyT2+ (glycinergic) cells, $F N$ fastigial nucleus, $G l y-F$ projecting GlyT2+ neurons of the fastigial nuclei, $G A D+I O$ small GABAergic neurons projecting to the inferior olive 
cells; and blue, non-spontaneously active GlyT2+ cells (GlyI). The GAD + neurons include both local and inferior oliveprojecting GABAergic neurons. Our own data from the GABAergic cells are strongly biased towards the larger (soma size $>12$ um) cells, among which we have observed no evidence for axons projecting outside the nucleus. The GABAergic neurons that project to the inferior olive (IO) have been described as very small $[18,19]$, and for this reason, we believe that they constitute a separate cell type, which we refer to as GAD+IO. To our knowledge, there are no studies that have specifically examined the electrophysiology of these small IO-projecting neurons. To acknowledge the undoubtedly great functional importance of this cell population, we have included the GAD+IO cells in our schematic representations while noting that a more detailed examination remains a goal for future studies.

\section{The Four DCN Neuron Subtypes Exhibit Distinct Active Membrane Properties}

In vitro and in vivo recordings from unidentified DCN neurons have revealed that the vast majority of these neurons are spontaneously active at action potential (AP) firing rates of $35-55 \mathrm{~Hz}$ driven by tonic cation currents [20-24]. Our recordings have confirmed that the major populations of DCN neurons that are likely to have been encountered in these previous recordings - namely GADnL, GADnS, and GAD + cells - are intrinsic AP generators, while a small population of large GlyT2-positive cells do not exhibit spontaneous activity (Fig. 2a and e). Because of their inactivity, we have termed these "glycine inactive" (Gly-I). Like the other three cell types, Gly-I cells can be driven to high-frequency firing by extrinsically imposed depolarization (Fig. 2b). However, Gly-I cells could not be made to fire continuously at high frequencies like the other cell types; instead, they tended to fire short bursts of fast APs. The GAD+IO neurons have not yet been carefully examined by intracellular recordings, but our few recordings suggest that they do exhibit spontaneous firing behavior that is similar to the local GABAergic neurons (mean firing frequency $7-10 \mathrm{~Hz}$ at $32^{\circ} \mathrm{C}$; $\mathrm{M}$. Uusisaari, unpublished observations).

Rather unexpectedly, the presumably GABAergic GAD+ cell population exhibits the greatest AP width (Fig. 2c, e), in contrast to the cerebral cortex, where many GABAergic interneurons are defined by their short-lasting APs. AP width in GAD- cells can be clustered into two groups with values above or below $0.6 \mathrm{~ms}$, suggesting the presence of more than one neuron population. In fact, plotting the AP width against cell capacitance suggested the existence of two cellular populations, one characterized by large size $\left(C_{\mathrm{m}}>100 \mathrm{pF}\right)$ and shorter APs and another being small in somatic size $\left(C_{\mathrm{m}}<100 \mathrm{pF}\right)$ with broader APs. These cell groups were respectively classified as GADnL and GADnS populations, divided by a (somewhat arbitrary) boundary value of $100 \mathrm{pF}$.

One attractive hypothesis is that these different AP widths are a consequence of different expression levels of delayed-rectifier type potassium channels, particularly, Kv3 subtypes [25, 26]. Our own studies [27, 28] and subsequent investigations by Joho and coworkers [29, 30] do not indicate a strong correlation between neuronal subtypes and Kv3 channel expression. However, it seems that Kv3 channel expression levels are somewhat lower in neurons containing GABA (local and/or IO-projecting) than in the large glutamatergic projection neurons, which would be consistent with GABAergic cells showing broader APs than glutamatergic ones.

AP width is not the only clearly distinguishing feature between GADnL and GADnS cells; GADnS cells also exhibit a stronger late component in the afterhyperpolarization (Fig. 2c, double arrowhead) and somewhat longer rebound depolarization and associated spiking after release from a hyperpolarizing step (Fig. 2d; [7, 31, 32]). With the exception of Gly-I cells, which have not yet been thoroughly characterized in this aspect, all cell types consistently show a pronounced sag in their response to hyperpolarizing current steps, indicative of hyperpolarization-activated cation current $\left(\mathrm{I}_{\mathrm{h}}\right.$ ) and rebound bursting that may involve the activity of Ttype calcium currents (Fig. 2d and e) [31, 33, 34]. As recently reviewed by Turner and coworkers [35], differences in rebound burst behavior may reflect distinct expression patterns of T-type calcium channel-forming $\mathrm{Ca}_{\mathrm{V}} 3$ isoforms. However, this study focused on spontaneously active largediameter neurons, and their data pool is unlikely to contain a significant fraction of the sparse, Gly-I neurons that are also characterized by lack of spontaneous activity. Our preliminary examinations of Gly-I cells suggest that these intrinsically silent neurons are also less prone to rebound bursting than the other, pacemaker-like neurons of the DCN (M. Uusisaari, unpublished observations).

Finally, these four cell types differ in spike frequency versus injected current density and their spike frequency accommodation. Most notably, GADnL neurons can be driven to the highest firing frequencies with a nearly linear current-frequency (I-F) relationship while also exhibiting the smallest amount of spike frequency adaption during sustained firing (Fig. 2e-iv, v). Local GAD + and GADnS cells respond to depolarization with saturating values of firing frequency, and show a significant amount of frequency adaptation. Again, this is in contrast to the situation in the cerebral cortex, where GABAergic interneurons typically fire at high and sustained frequencies. The Gly-I cells exhibit the strongest accommodation, to the extent that they tend to stop firing 
a Cell-attached recordings, voltage clamp

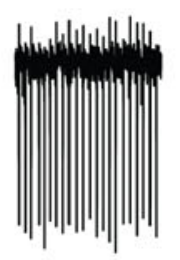

GADnL

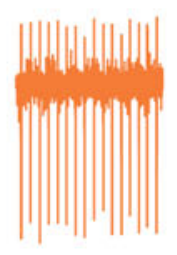

GADnS

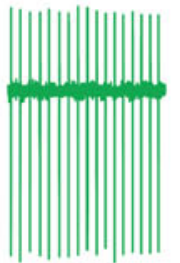

GAD+

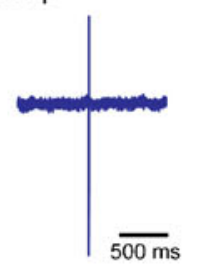

Gly-I

\section{b Whole-cell, current clamp}
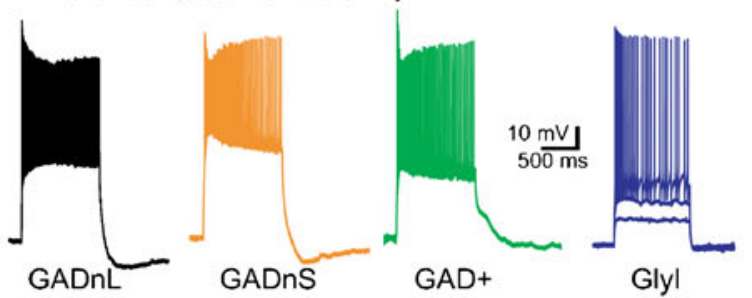

C
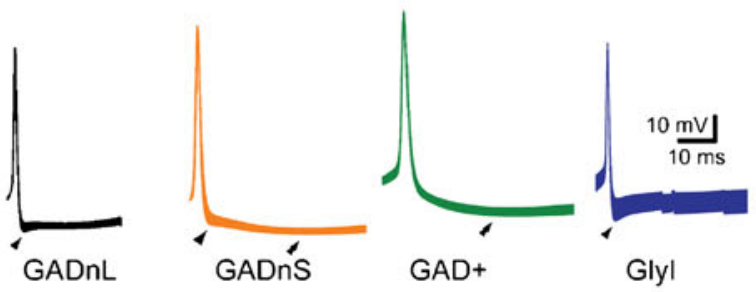

d

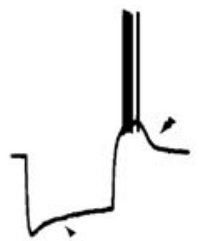

GADnL

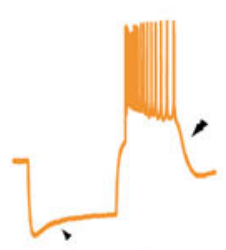

GADnS

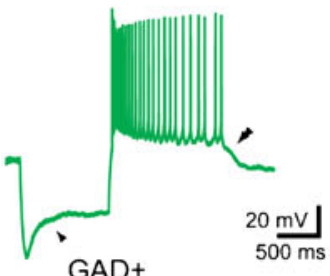

$20 \mathrm{mV}$

GAD+

e
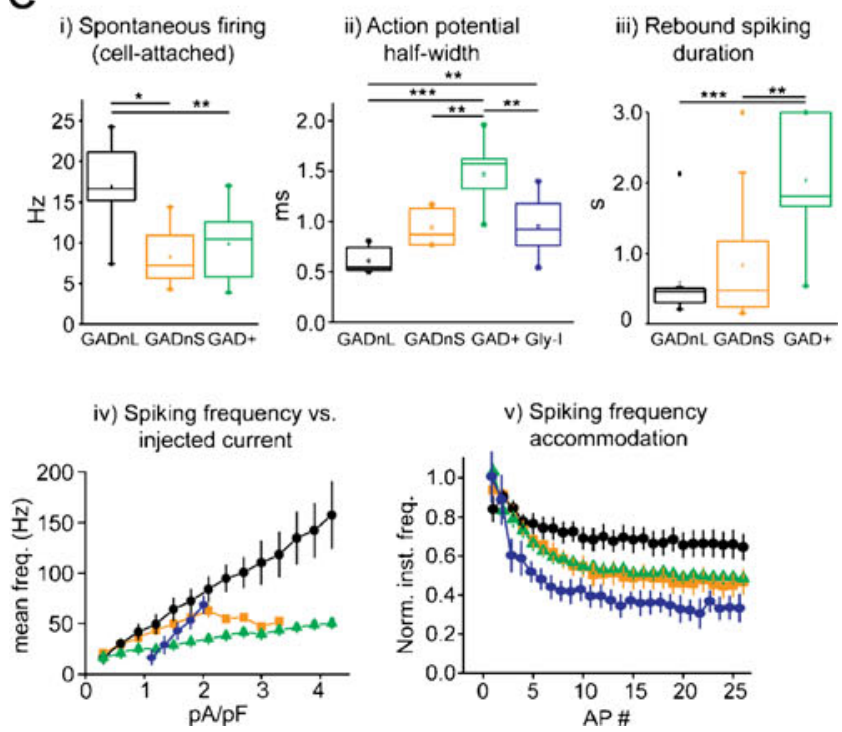

Fig. 2 Action potential firing properties of DCN neurons. a Example traces from cell-attached voltage-clamp recordings. With the exception of Gly-I cells, all cell types fire regularly with a frequency much greater than $0.1 \mathrm{~Hz}$. b Example traces showing voltage responses to depolarizing current injections (1-s, $1.5 \mathrm{pA} / \mathrm{pF}$ for GADnL, GADnS, and GAD+; $0.9,1.5$, and $2.4 \mathrm{pA} / \mathrm{pF}$ for Gly-I). Note the higher firing rheobase in Gly-I cell. c Peak-aligned, averaged action potentials; width of the trace represents \pm SEM. Single arrowheads mark fast afterhyperpolarization, double arrowheads mark slow afterhyperpolarization. d Example traces showing voltage responses to hyperpolarizing current injections $(1-\mathrm{s},-1.5 \mathrm{pA} / \mathrm{pF})$. GADnL, GADnS, and $\mathrm{GAD}+$ cells displayed $\mathrm{I}_{\mathrm{h}}$-indicating voltage sags (single arrowhead) and pronounced rebound depolarization and associated firing (double arrowhead). e Statistical summaries of key electrophysiological parameters. $i$ Spontaneous firing frequency under cell-attached conditions. Note that Gly-I cells did not spontaneously fire continuously. ii Action potential half width, measured from repetitively fired action potentials at room temperature $\left(\mathrm{RT} ; 24^{\circ} \mathrm{C}\right)$. iii Duration of rebound depolarization and associated spiking at half-amplitude at RT. Note that Gly-I cells never fired spikes on rebound. iv Mean firing frequency during a step depolarization versus injected current. Note that in order to enable meaningful comparison of I-F curves in cells of significantly different sizes, the injected current is given in relative units of $\mathrm{pA} / \mathrm{pF}$. $v$ Spiking frequency adaptation during a step depolarization that evoked $\sim 40 \mathrm{~Hz}$ (GADnL, GADnS, and GAD+) or $\sim 30 \mathrm{~Hz}$ (Gly-I) firing. Data in a-d are modified from [11] and [12]. Panels from e were modified from the following sources: $i$ and iii from [11], ii from [48], and $i v$ and $v$ from a combination of [11] with [48]. Asterisks denote statistical significance: ${ }^{*} p<0.05,{ }^{* *} p<0.01$, and $* * * p<0.001$; non-significant differences are left unlabeled for visual clarity

after a few initial spikes. It would thus seem that the DCN neurons cover a range of signal transduction modes, from tonic firing and rate-coding (GADnL) to burst-firing and onset or time-interval coding (GAD+, Gly-I).

\section{Morphometric Parameters of the DCN Neuron Subtypes}

Classical [5] and more recent studies [6-8] have attempted to classify DCN neurons on the basis of their morphology. These cells vary considerably in terms of dendritic arborization and axonal branching, and these efforts have revealed no strong correlation between simple dendritic morphologies and electrophysiological characteristics [8]. Our own set of $\sim 100$ biocytin-filled GAD+, GAD-, and GlyT2+ cells included neurons with axons that either coursed locally or projected to more distant targets. In general, neurons with larger cell bodies exhibited more complex dendritic morphology (Fig. 3), and this complexity undoubtedly enables these cells to perform non-linear integration of synaptic information. The concentration of synaptic contacts from the collaterals of mossy and climbing fibers on the dendrites of these 
Fig. 3 Variability in DCN neuron morphology.

Representative examples of the five DCN neuronal classes stained with biocytin and comparison of cell body sizes between cells responding to three different neurotransmitters. Arrowheads point to axons; insets show dendritic spines at higher magnification. Scale bar-20 $\mu \mathrm{m}$ for main images, $5 \mu \mathrm{m}$ for insets. Note that despite the differences in average cell body size between cell types, these values overlap considerably between groups. Panels are modified from [11] and [48]. Asterisks denote statistical significance: $* * * p<0.001$
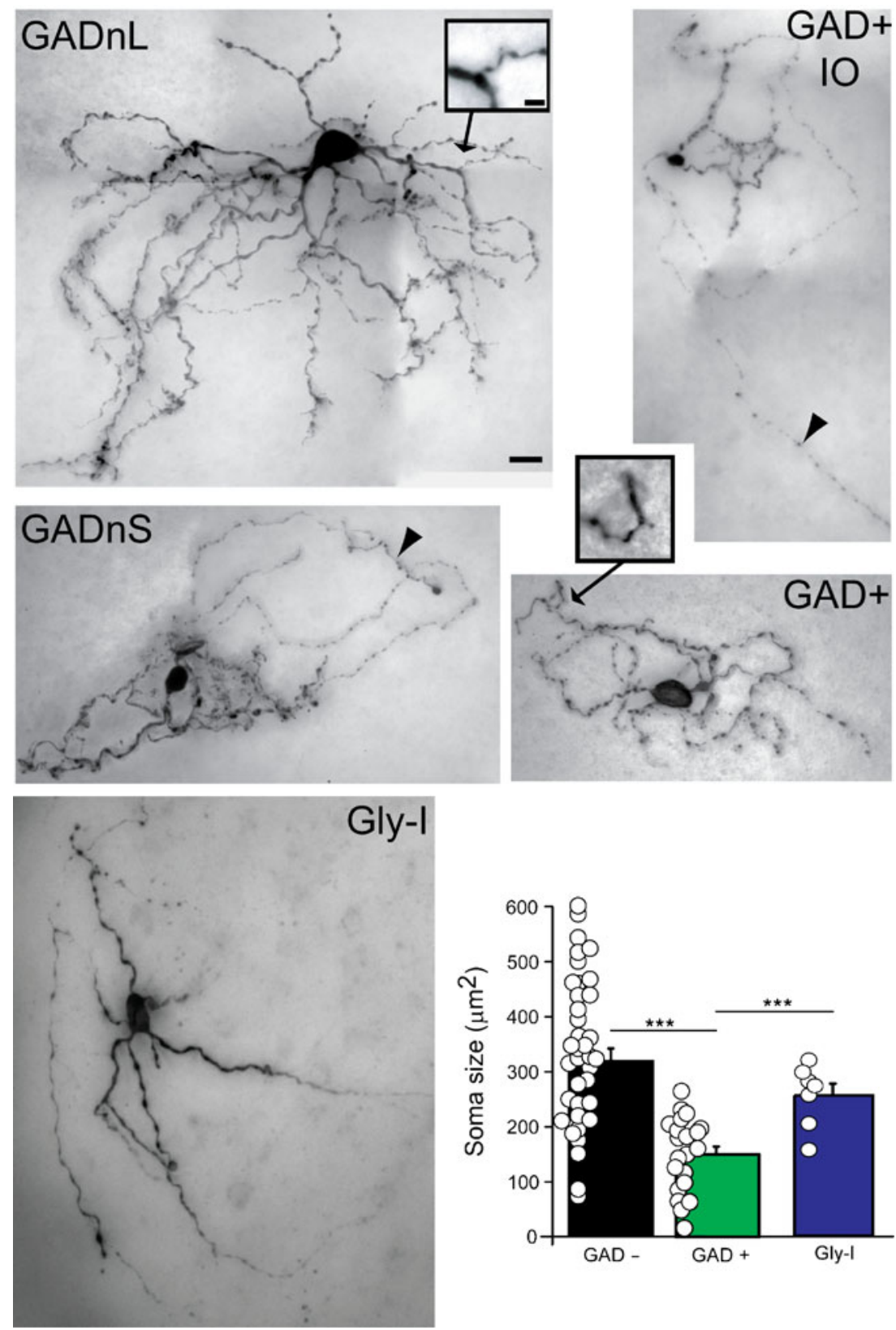

cells is in keeping with their elaborate computational properties [5].

Despite the cell-to-cell variability of dendritic structures, the above-described subtypes could not be readily identified by their morphology alone, even with information about GAD67 expression. Indeed, quantitative analysis of several measures of dendritic morphology and, surprisingly, cell body size revealed clearly overlapping distributions [11]. Importantly, GAD + cells could not be reliably differentiated from GAD- cells on the basis of cell body size, and the Gly-I cells described in [12] also significantly overlap with GAD- cells in terms of cell body size. Since many of the electrophysiological recordings found in literature are reported to originate from "large DCN neurons," these data are likely biased towards glutamatergic cells, but presumably also include GABAergic or glycinergic cells. Since the electrophysiological differences between GAD+ and GAD- cells are subtle, it is not surprising that most reports did not find clearly distinguishable cell types. In this context, it should be noted that the Gly-I cells might have been omitted in previous slice studies as "unhealthy cells," as they are not necessarily spontaneously active. This is unfortunate, as our targeted staining of these silent, GlyT2 + cells 
revealed that they project directly to the cerebellar cortex, unlike any other cell type that we have encountered in the DCN so far [12], making further elucidation of their behavior mandatory. The actual synaptic targets within the cerebellar cortex remain unknown for these putatively glycinergic - and thus, inhibitory-neurons, but are likely to be cerebellar Golgi cells as these are the only neurons in most areas of the cerebellar granule cell layer that express glycine receptors [36].

\section{Spontaneous Synaptic Activity of DCN Neuron Subtypes}

Purkinje neuron (PN) axons from the cerebellar cortex provide the main efferent input to the DCN, and this is their main target. Based on counts of Purkinje and DCN neurons (estimates for mouse are $\sim 200,000$ PNs [37] and $\sim 30,000$ neurons in all three DCN [38]), signal transmission from the cortex to the nuclei shows overall convergence, but the true extent of this convergence at the cellular level is not known. Based on the count of Purkinje axon terminals on large DCN cell bodies, and taking into account various estimates of how many terminals a single axon will form on a given neuronal body and the spread of PN axons within the nuclei, estimates of the number of PNs contacting a single large DCN neuron range between several tens and several hundreds [39-41]. Despite anatomical evidence [5, 42] suggesting that the number of PN synapses on DCN cells is variable across different types of DCN cells, it is generally assumed that all DCN neurons are equally controlled by PN activity.

However, since most work examining GABAergic synaptic currents in DCN [43-47] has focused on largediameter neurons, which presumably correspond primarily to GADnL neurons, some of the above conclusions will need to be revisited with regard to different neuronal subtypes. To clarify whether PN input is comparable across different DCN neuronal types, we have studied the properties of spontaneously occurring inhibitory postsynaptic currents (IPSCs) in DCN cells, taking advantage of the fact that spontaneous release does not require intact Purkinje neuron-DCN connections, which are rare in slice preparations [48]. Whole-cell voltage-clamp recordings using high-chloride intracellular solution $\left(E_{\mathrm{rev} \mathrm{Cl}^{-}} \sim 0 \mathrm{mV}\right)$ revealed a striking difference between $\mathrm{GAD}+$ and GADneurons. Both GADnL and GADnS cells were under constant bombardment of spontaneous, tetrodotoxininsensitive IPSCs with kinetics similar to those described previously for Purkinje-DCN synapses [45], but GAD+ neurons received only very infrequent IPSCs with slower kinetics and much smaller amplitudes (Fig. 4). Our initial hypothesis was that these differing kinetics were simply the result of differential expression of GABAaR subunits in these cell types. Experiments using GABAaR subunitspecific agents [48] revealed that there are, indeed, differences in GABAaR subunit composition between the DCN cell types. However, these differences are not the only cause for the observed differences in IPSC kinetics as IPSCs in both GAD + and GADnS cells proved sensitive to selective up-modulators for the alpha1 and alpha3 subunits. These experiments revealed an additional and rather intriguing cause for the difference in IPSC kinetics: whereas IPSCs in GAD- neurons could be recorded immediately upon breaking into whole-cell mode, IPSCs in GAD + cells usually became apparent only tens of seconds after establishing a whole-cell configuration (Fig. 4c, upper left). This led to the proposition that GABAergic synapses on GAD + cells are predominantly formed on distal dendrites rather than cell bodies; on the other hand, PNs form large numbers of synapses on the bodies of large glutamatergic DCN neurons, to the extent that GAD - cell bodies seem to be entirely covered by GABAergic presynaptic terminals [5, 11]. Notably, large DCN neurons (GADnL) are also most likely to exhibit distal GABAergic inputs that generate slower and smaller-amplitude synaptic events, although those may be masked by the larger events triggered by proximal synapses. Taken together, it appears that the slower IPSC time course seen in GAD + cells arises from a combination of distal dendritic localization of synapses and a specific receptor subtype composition, as well as possible differences in the spatiotemporal dynamics of GABA release [3, 45, 49].

Unfortunately, we have only limited data on the properties of the synaptic inputs to Gly-I cells. Preliminary results obtained in our laboratory suggest that these cells resemble GADnS cells more than GAD+ cells with respect to IPSC kinetics and frequency (M. Uusisaari, unpublished observations), which suggests that Gly-I cell bodies are being targeted by Purkinje neuron axons. As Gly-I cells seem to be endowed with the capability to control cerebellar cortical activation via their putative inhibitory synaptic contacts in the granule cell layer, elucidation of their afferent inputs is a pressing open task.

\section{Synaptic Inputs to DCN Neuron Subtypes}

Working from our present understanding of these various functionally different classes of neurons, a partial picture on the ins and outs to the DCN emerges (Fig. 5). Based on histological evidence, the PNs are known to synapse on GADnL and GAD+IO neurons [18, 42], but the extent to which PNs innervate other cell types is less well 


\section{a Voltage clamp, high-Cl electrode $\left(24^{\circ} \mathrm{C}\right)$}

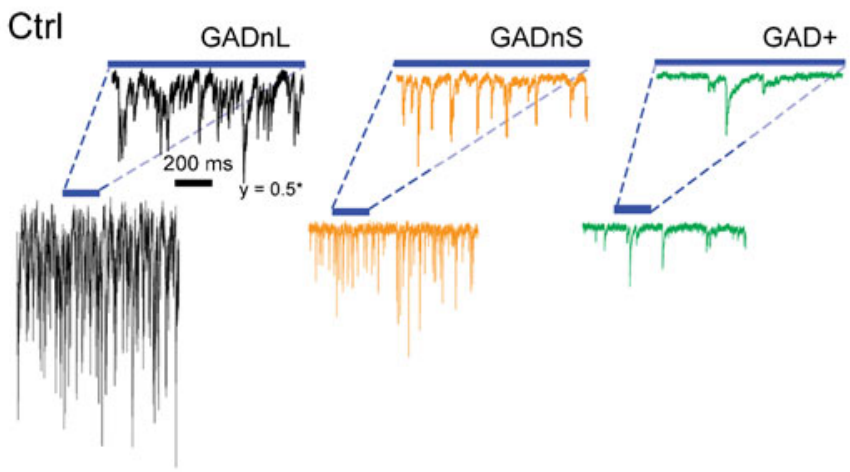

b

\section{i) IPSC frequency $\left(24^{\circ} \mathrm{C}\right)$}

ii) Avg. IPSCs $\left(32^{\circ} \mathrm{C}\right)$

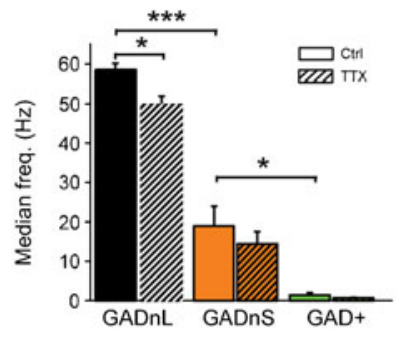

iii) $10-90 \%$ rise $\left(32^{\circ} \mathrm{C}\right)$
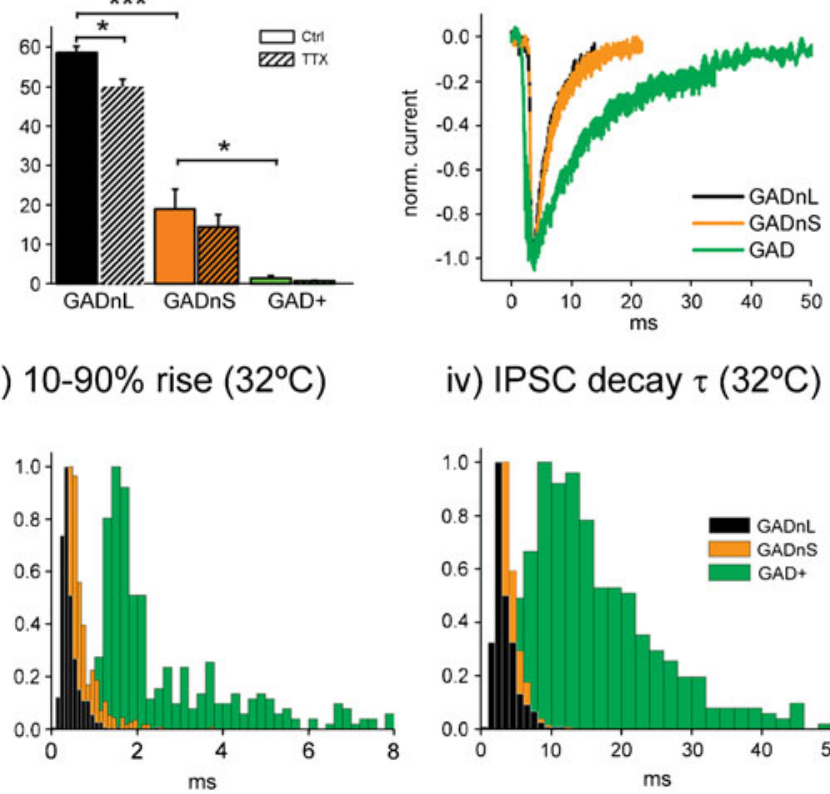

iv) IPSC decay $\tau\left(32^{\circ} \mathrm{C}\right)$

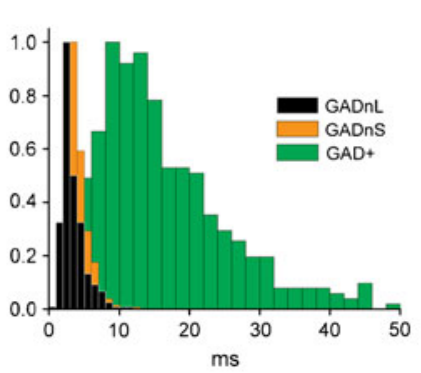

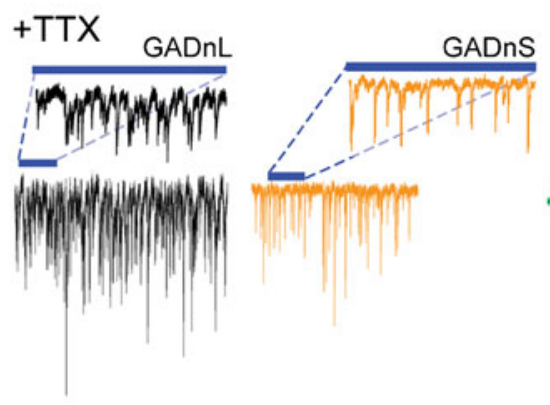

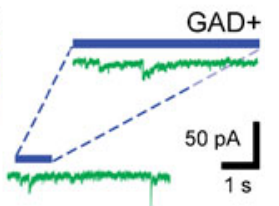

C

i) IPSC frequency

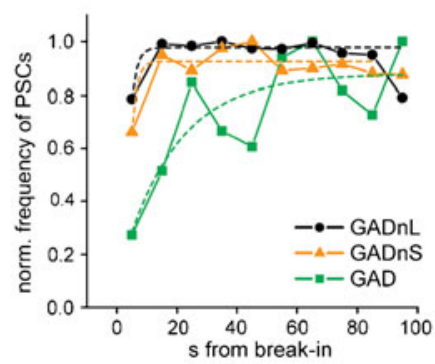

iii) Shortly after break-in

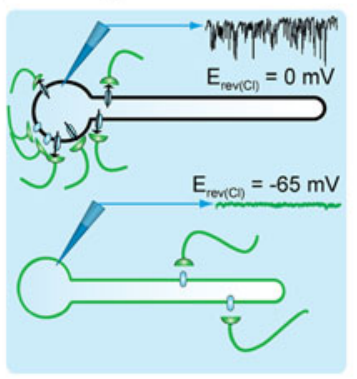

ii) Before break-in

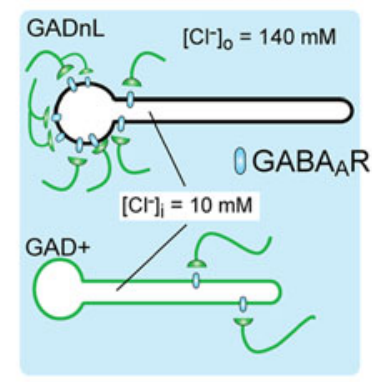

iv) $\mathrm{Cl}$ - equilibrated

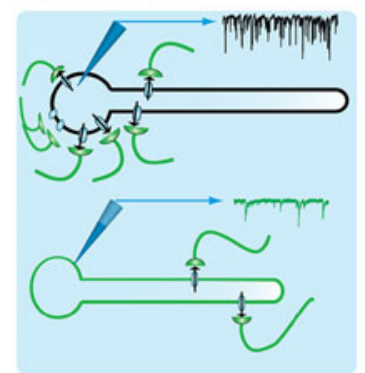

Fig. 4 Spontaneous IPSCs in GADnL, GADnS, and GAD+ cells. All recordings in this figure were obtained using a high- $\mathrm{Cl}^{-}$internal solution $\left(E_{\text {rev }}\right.$ GABA $\sim 0 \mathrm{mV}$ ). a Spontaneous IPSCs are not notably affected by tetrodotoxin (TTX). $i$ Example traces of IPSCs in control conditions (upper panel) and with added TTX (lower panel). Insets show IPSCs with an expanded time scale. Note that for GADnL cells, the current axis is compressed twofold. ii Statistical comparison of IPSC frequency between cell groups with and without TTX. The decrease in IPSC frequency was not significant in any of the cell groups. b IPSC kinetics in GAD+ cells are significantly slower than in GADnL and GADnS cells. $i$ comparison of IPSC occurrence frequency between the cell types in control (solid color bars) and TTX (hatched bars). Asterisks denote statistical significance: $* p<$ $0.05, * * * p<0.001$. Non-significant differences between control and TTX conditions are left unmarked. ii Averaged, peak-aligned, and normalized IPSC shapes. Width of the trace indicates \pm SEM. iii-iv Comparison of $10-90 \%$ rise time and decay time constant distributions at $32^{\circ} \mathrm{C}$. Note the broad spread of both measured values in GAD+ cells. c Delayed appearance of IPSCs suggests distal location of GABAaRs in GAD+ cells. $i$ Normalized frequency of IPSCs as a function of time since breaking into whole-cell configuration. $i i-i v$ Suggested mechanism behind the delayed appearance of IPSCs. Upon breaking into whole-cell configuration, the reversal potential of GABA-mediated $\mathrm{Cl}^{-}$ currents $\left(E_{\text {rev }}\right.$ GABAa $)$ near somatic GABAaRs on GADnL cells is quickly shifted to $0 \mathrm{mV}$, providing inward driving force for chloride and thereby permitting IPSC measurements. On the other hand, the $E_{\text {rev }}$ GABAa near GABAaRs located in distal dendrites is shifted more slowly, requiring diffusion of $\mathrm{Cl}^{-}$from the soma to the dendrites. a-c $(i)$ are modified from [48] established. Our electrophysiological data suggest that GADnS cells are contacted by PN axons to the same extent as GADnL cells, while GAD + cells are innervated to perhaps a lesser degree, based on the different properties of spontaneous IPSCs in these cells [48]. Bagnall and coworkers [50] have reported that the large, 
Fig. 5 Schematic drawing of the putative synaptic connections for the different DCN neuron types. Arrows with dashed lines denote axons of local DCN neurons or collaterals of efferent axons. Note that few of the depicted synaptic connections have been unequivocally demonstrated. $P N$ Purkinje neuron axon, $M F C$ mossy fiber collateral, $C F C$ climbing fiber collateral, $C C t x$ cerebellar cortex, GlyR glycine receptor, GABAaR GABAa receptor, $A M P A R / N M D A R$ AMPA and/or NMDA receptor

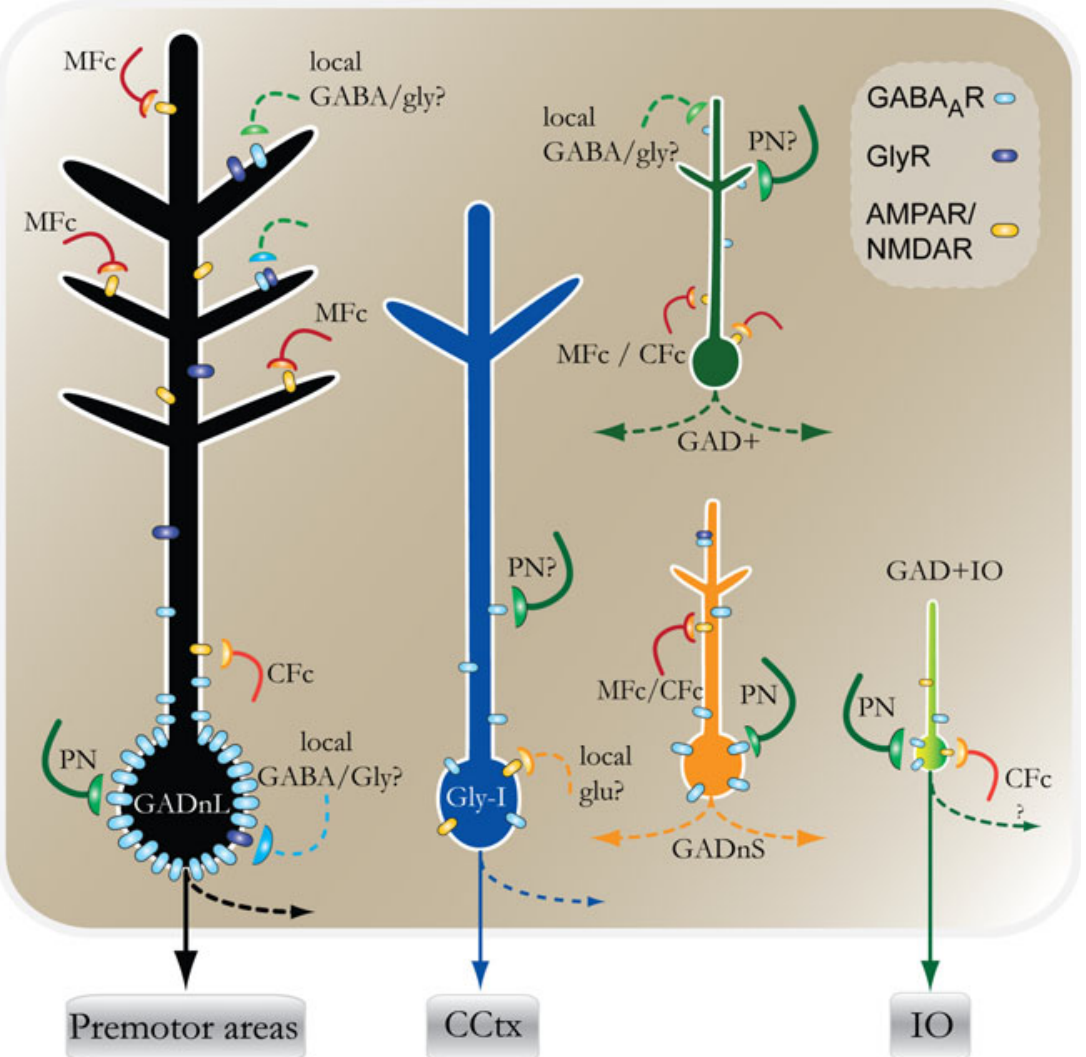

glycinergic projection neurons of the fastigial nucleus appear to be under PN control, even though it is unclear whether PN synapses are present on the Gly-I neurons in the lateral nucleus. Conversely, it is known that climbing fiber $(\mathrm{CF})$ collaterals contact both $\mathrm{GAD}+\mathrm{IO}$ and GADnL DCN neurons and that mossy fiber (MF) collaterals synapse on GADnL cells, but the relative strength of these connections and whether MF or CF synapses occur on other cell types is unknown [5, 19]. Unpublished observations from our laboratory suggest, however, that both $\mathrm{GAD}+$ and GADnS cells receive glutamatergic extracerebellar synaptic afferents (M. Uusisaari, unpublished observations). Notably, the roles and targets of inhibitory DCN interneurons are entirely unknown, even though non-Purkinje GABAergic presynaptic terminals have been described on both GABAergic and glutamatergic DCN neurons.

Clearly, we presently lack even a basic description of all of the various cell types in the DCN and are far from compiling a circuit diagram that reflects an understanding of their functional properties. Fundamental issues that need to be addressed in future work include the examination of the neurons that project from the DCN to the IO, determining the extent to which our observations in the lateral nucleus can be generalized to the other two nuclei, and the completion of a careful histological examination of the spatial distribution of cell types within the different nuclei [6]. Following on the identification of these different cell types, we also need to examine their afferent and intrinsic connections. Notably, previous studies aimed at characterizing the properties of MF and CF synapses were specifically biased towards large neurons, whereas there is clear anatomical evidence for afferent connections targeting different cell types [5]. Even less is known about the functional role of the connectivity within the DCN, which is likely to consist of local GABAergic, glutamatergic, and glycinergic synaptic communication $[5,51,52]$. It seems likely that the DCN is organized in a modular fashion, since afferent and efferent connections segregate according to their extra-nuclear sources [53]. There is a possibility that synaptic crosstalk may occur between these modules in a manner analogous to the parallel fibers that provide information flow across the zones of the cerebellar cortex.

Finally, future research efforts should explore the possible function of inhibitory nucleo-cortical synaptic connections formed by Gly-I cell axons [54-56]. Our growing toolbox of mouse strains in which neuronal subtypes are conveniently identifiable via cell typespecific expression of fluorescent protein reporters, in conjunction with techniques for neural circuit labeling via 
transsynaptic gene delivery, should enable us to effectively address these issues in the years to come [57].

Conflict of Interest The authors declare that they have no conflict of interest with respect to this article.

Open Access This article is distributed under the terms of the Creative Commons Attribution Noncommercial License which permits any noncommercial use, distribution, and reproduction in any medium, provided the original author(s) and source are credited.

\section{References}

1. Eccles SJC, Itō M, Szentágothai J. The cerebellum as a neuronal machine. Springer-Verlag; 1967.

2. Aizenman CD, Linden DJ. Rapid, synaptically driven increases in the intrinsic excitability of cerebellar deep nuclear neurons. Nat Neurosci. 2000;3:109-11.

3. Pugh JR, Raman IM. Mechanisms of potentiation of mossy fiber EPSCs in the cerebellar nuclei by coincident synaptic excitation and inhibition. J Neurosci. 2008;28:10549-60.

4. Zheng N, Raman IM. Synaptic inhibition, excitation, and plasticity in neurons of the cerebellar nuclei. Cerebellum. 2010;9:56-66.

5. Chan-Palay V. Cerebellar Dentate Nucleus: Organization, Cytology and Transmitters. Springer-Verlag; 1977.

6. Sultan F, Czubayko U, Thier P. Morphological classification of the rat lateral cerebellar nuclear neurons by principal component analysis. J Comp Neurol. 2003;455:139-55.

7. Czubayko U, Sultan F, Thier P, Schwarz C. Two types of neurons in the rat cerebellar nuclei as distinguished by membrane potentials and intracellular fillings. J Neurophysiol. 2001;85:2017-29.

8. Aizenman CD, Huang EJ, Linden DJ. Morphological correlates of intrinsic electrical excitability in neurons of the deep cerebellar nuclei. J Neurophysiol. 2003;89:1738-47.

9. Tamamaki N, Yanagawa Y, Tomioka R, et al. Green fluorescent protein expression and colocalization with calretinin, parvalbumin, and somatostatin in the GAD67-GFP knock-in mouse. J Comp Neurol. 2003;467:60-79.

10. Zeilhofer HU, Studler B, Arabadzisz D, et al. Glycinergic neurons expressing enhanced green fluorescent protein in bacterial artificial chromosome transgenic mice. J Comp Neurol. 2005;482:123-41.

11. Uusisaari M, Obata K, Knöpfel T. Morphological and electrophysiological properties of GABAergic and non-GABAergic cells in the deep cerebellar nuclei. J Neurophysiol. 2007;97:901-11.

12. Uusisaari M, Knöpfel T. GlyT2+ neurons in the lateral cerebellar nucleus. Cerebellum. 2010;9:42-55.

13. Voogd J. Cerebellum. In: Paxinos G, editor. The rat nervous system. 3rd ed. San Diego: Elsevier, Academic; 2004. p. 205-42.

14. Glickstein M, Strata P, Voogd J. Cerebellum: history. Neuroscience. 2009;162:549-59.

15. Mauk MD. Roles of cerebellar cortex and nuclei in motor learning: contradictions or clues? Neuron. 1997;18:343-6.

16. Bengtsson F, Hesslow G. Cerebellar control of the inferior olive. Cerebellum. 2006;5:7-14.

17. Sugihara I, Shinoda Y. Molecular, topographic, and functional organization of the cerebellar nuclei: analysis by threedimensional mapping of the olivonuclear projection and aldolase C labeling. J Neurosci. 2007;27:9696-710.

18. Teune TM, van der Burg J, de Zeeuw CI, Voogd J, Ruigrok TJ. Single Purkinje cell can innervate multiple classes of projection neurons in the cerebellar nuclei of the rat: a light microscopic and ultrastructural triple-tracer study in the rat. J Comp Neurol. 1998;392:164-78.

19. De Zeeuw CI, Van Alphen AM, Hawkins RK, Ruigrok TJ. Climbing fibre collaterals contact neurons in the cerebellar nuclei that provide a GABAergic feedback to the inferior olive. Neuroscience. 1997;80:981-6.

20. Thach WT. Discharge of Purkinje and cerebellar nuclear neurons during rapidly alternating arm movements in the monkey. J Neurophysiol. 1968;31:785-97.

21. LeDoux MS, Hurst DC, Lorden JF. Single-unit activity of cerebellar nuclear cells in the awake genetically dystonic rat. Neuroscience. 1998;86:533-45.

22. Raman IM, Gustafson AE, Padgett D. Ionic currents and spontaneous firing in neurons isolated from the cerebellar nuclei. J Neurosci. 2000;20:9004-16.

23. Rowland NC, Jaeger D. Coding of tactile response properties in the rat deep cerebellar nuclei. J Neurophysiol. 2005;94:1236-51.

24. Rowland NC, Jaeger D. Responses to tactile stimulation in deep cerebellar nucleus neurons result from recurrent activation in multiple pathways. J Neurophysiol. 2008;99:704-17.

25. Rudy B, McBain CJ. Kv3 channels: voltage-gated K+ channels designed for high-frequency repetitive firing. Trends Neurosci. 2001;24:517-26.

26. McMahon A, Fowler SC, Perney TM, Akemann W, Knöpfel T, Joho R. Allele-dependent changes of olivocerebellar circuit properties in the absence of the voltage-gated potassium channels Kv3.1 and Kv3.3. Eur J Neurosci. 2004;19:3317-27.

27. Uusisaari M, Obata K, Knöpfel T. Electrophysiological and morphological analysis of GABAergic and glutamatergic cells of the deep cerebellar nuclei. Program No. 297.82005 Neuroscience Meeting Planner. Washington, DC: Society for Neuroscience; 2005.

28. Alonso-Espinaco V, Elezgarai I, Díez-García J, Puente N, Knöpfel T, Grandes P. Subcellular localization of the voltage-gated potassium channels $\mathrm{Kv} 3.1 \mathrm{~b}$ and $\mathrm{Kv} 3.3$ in the cerebellar dentate nucleus of glutamic acid decarboxylase 67-green fluorescent protein transgenic mice. Neuroscience. 2008;155:1059-69.

29. Joho R, Hurlock E. The role of Kv3-type potassium channels in cerebellar physiology and behavior. Cerebellum. 2009;8:323-33.

30. Hurlock EC, Bose M, Pierce G, Joho RH. Rescue of motor coordination by purkinje cell-targeted restoration of Kv3.3 channels in Kcnc3-null mice requires Kcnc1. J Neurosci. 2009;29:15735-44.

31. Jahnsen H. Electrophysiological characteristics of neurones in the guinea-pig deep cerebellar nuclei in vitro. J Physiol. 1986;372:129-47.

32. Aizenman CD, Linden DJ. Regulation of the rebound depolarization and spontaneous firing patterns of deep nuclear neurons in slices of rat cerebellum. J Neurophysiol. 1999;82:1697-709.

33. Muri R, Knöpfel T. Activity induced elevations of intracellular calcium concentration in neurons of the deep cerebellar nuclei. $\mathrm{J}$ Neurophysiol. 1994;71:420-8.

34. Alviña K, Ellis-Davies G, Khodakhah K. T-type calcium channels mediate rebound firing in intact deep cerebellar neurons. Neuroscience. 2009;158:635-41.

35. Tadayonnejad R, Anderson D, Molineux M, et al. Rebound discharge in deep cerebellar nuclear neurons in vitro. Cerebellum. 2010;9:352-74.

36. van den Pol A, Gorcs T. Glycine and glycine receptor immunoreactivity in brain and spinal cord. J Neurosci. 1988;8:472-92.

37. Woodruff-Pak D. Stereological estimation of Purkinje neuron number in $\mathrm{C} 57 \mathrm{BL} / 6$ mice and its relation to associative learning. Neuroscience. 2006;141:233-43.

38. Sultan F, König T, Möck M, Thier P. Quantitative organization of neurotransmitters in the deep cerebellar nuclei of the Lurcher mutant. J Comp Neurol. 2002;452:311-23. 
39. Palkovits M, Mezey E, Hámori J, Szentágothai J. Quantitative histological analysis of the cerebellar nuclei in the cat. I. Numerical data on cells and on synapses. Exp Brain Res. 1977;28:189-209.

40. Shepherd GM. The synaptic organization of the brain. Oxford University Press; 2004.

41. Sugihara I, Fujita H, Na J, et al. Projection of reconstructed single purkinje cell axons in relation to the cortical and nuclear aldolase C compartments of the rat cerebellum. J Comp Neurol. 2009;512:282-304.

42. De Zeeuw CI, Berrebi AS. Postsynaptic targets of Purkinje cell terminals in the cerebellar and vestibular nuclei of the rat. Eur $\mathbf{J}$ Neurosci. 1995;7:2322-33.

43. Sastry BR, Morishita W, Yip S, Shew T. GABA-ergic transmission in deep cerebellar nuclei. Prog Neurobiol. 1997;53:259-71.

44. Anchisi D, Scelfo B, Tempia F. Postsynaptic currents in deep cerebellar nuclei. J Neurophysiol. 2001;85:323-31.

45. Telgkamp P, Raman IM. Depression of inhibitory synaptic transmission between purkinje cells and neurons of the cerebellar nuclei. J Neurosci. 2002;22:8447-57.

46. Pedroarena CM, Schwarz C. Efficacy and short-term plasticity at GABAergic synapses between purkinje and cerebellar nuclei neurons. J Neurophysiol. 2003;89:704-15.

47. Telgkamp P, Padgett DE, Ledoux VA, Woolley CS, Raman IM. Maintenance of high-frequency transmission at purkinje to cerebellar nuclear synapses by spillover from boutons with multiple release sites. Neuron. 2004;41:113-26.

48. Uusisaari M, Knöpfel T. GABAergic synaptic communication in the GABAergic and non-GABAergic cells in the deep cerebellar nuclei. Neuroscience. 2008;156:537-49.
49. Pugh JR, Raman IM. GABAA receptor kinetics in the cerebellar nuclei: evidence for detection of transmitter from distant release sites. Biophys J. 2005;88:1740-54.

50. Bagnall MW, Zingg B, Sakatos A, Moghadam S, Zeilhofer H, du Lac S. Glycinergic projection neurons of the cerebellum. J Neurosci. 2009;29:10104-10.

51. Chen S, Hillman DE. Colocalization of neurotransmitters in the deep cerebellar nuclei. J Neurocytol. 1993;22:81-91.

52. Bäurle J, Grüsser-Cornehls U. Differential number of glycine- and GABA-immunopositive neurons and terminals in the deep cerebellar nuclei of normal and Purkinje cell degeneration mutant mice. J Comp Neurol. 1997;382:443-58.

53. Apps R, Garwicz M. Anatomical and physiological foundations of cerebellar information processing. Nat Rev Neurosci. 2005;6:297311.

54. Angaut P, Compoint C, Buisseret-Delmas C, Batini C. Synaptic connections of Purkinje cell axons with nucleocortical neurones in the cerebellar medial nucleus of the rat. Neurosci Res. 1996;26:345-8.

55. Batini C, Buisseret-Delmas C, Compoint C, Daniel H. The GABAergic neurones of the cerebellar nuclei in the rat: projections to the cerebellar cortex. Neurosci Lett. 1989;99:251-6.

56. Batini C, Compoint C, Buisseret-Delmas C, Daniel H, Guegan M. Cerebellar nuclei and the nucleocortical projections in the rat: retrograde tracing coupled to GABA and glutamate immunohistochemistry. J Comp Neurol. 1992;315:74-84.

57. Akemann W, Middleton SJ, Knöpfel T. Optical imaging as a link between cellular neurophysiology and circuit modeling. Front Cell Neurosci. 2009;3:5. 